\title{
A REVIEW ON RECENT AVAILABLE POSITIONING TECHNOLOGIES AND ITS ADVANCEMENT
}

\author{
Chai Nee Ping ${ }^{*}$, Wan Azlan Wan Zainal Abidin ${ }^{1}$, Wan Hashim Wan Ibrahim², Kis- \\ met Anak Hong Ping ${ }^{1}$
}

${ }^{1}$ Department of Electronic Engineering, Faculty of Engineering, Universiti Malaysia Sarawak (UNIMAS), Kota Samarahan, Sarawak, Malaysia.

${ }^{2}$ Department of Civil Engineering, Faculty of Engineering, Universiti Malaysia Sarawak (UNIMAS), Kota

Samarahan, Sarawak, Malaysia.

*Corresponding author: chaineeping@gmail.com

\begin{abstract}
This paper reviews and compares the available positioning technology for location based application such as the Intelligent Transport System (ITS) and personal vehicle positioning. With the rapid growing trend of worldwide vehicle ownership, issues such as traffic congestion, environmental pollution, energy consumption and road accident cases are increasing. Intelligent Transportation System (ITS) which depends on location and positioning has been identified as one of the advocated key to resolve the issues. Global Positioning System (GPS) is one of the most promising ubiquitous positioning technologies accepted worldwide for ITS application. It is discerned that GPS alone in ITS application is not adequate since GPS faced Non-Line-of-Sight (NLOS) and multipath effect. New technology integrated is needed to overcome the drawback of the current system for continuous positioning; particularly important for ITS application to be fully functional. This is the significant motivation for tremendous research works had been carried out to improve the performance of positioning. In this paper, advantages and disadvantages of the recent available positioning technologies being used in the implementation of ITS such as satellite-based positioning, network-based positioning and location integration of several positioning technologies is found to be able to improve accuracy, reliability, availability and applicability of the ITS.
\end{abstract}

\begin{abstract}
ABSTRAK Kertas kerja ini membandingkan teknologi penentududukan untuk aplikasi berasaskan lokasi seperti Intelligent Transportation System (ITS) serta penentududukan bagi kenderaan persendirian. Dengan trend pemilikan kenderaan yang meningkat di seluruh dunia, isu-isu seperti kesesakan lalu lintas, pencemaran alam sekitar, penggunaan tenaga dan kes-kes kemalangan jalan raya semakin serius. Intelligent Transportation System (ITS) yang bergantung kepada maklumat lokasi dan penentududukan telah dikenal pasti sebagai salah satu kaedah yang dapat membantu menyelesaikan isu-isu tersebut. Global Positioning System (GPS) adalah salah satu daripada teknologi penentududukan yang diterimapakai di seluruh dunia bagi aplikasi ITS. Namun begitu, teknologi GPS sahaja adalah tidak memadai kerana masalah Non-Line- of-Sight (NLOS) dan kesan berbilang arah (multipath). Bagi mengatasi kelemahan sistem GPS dan untuk membolehkan ITS berfungsi sepenuhnya, penentududukan yang berterusan adalah penting tanpa masalah NLOS dan kesan berbilang arah. Masalah ini telah menjadi satu motivasi kepada penyelidikan bagi menambahbaik prestasi sistem penentududukan. Kebaikan dan keburukan teknologi baru penentududukan yang ada digunakan dalam pelaksanaan ITS seperti penentududukan berasaskan satelit, penentududukan berasaskan rangkaian dan Integrasi lokasi beberapa teknologi kedudukan didapati dapat meningkatkan ketepatan, kebolehpercayaan, ketersediaan dan kebolehgunaan aplikasi ITS .
\end{abstract}

(Keywords: Positioning technologies, GPS, NLOS, multipath effect, integration)

\section{INTRODUCTION}

Increase in the use of private vehicles is a common phenomenon in developed and developing countries. The number of vehicles in the world is increasing from year to year [1]. The increase of average annual percentage of registration from 1960 to 2010 is only $2.3 \%$ [2], the guesstimate number of vehicle is around 12 million. The increase of number of vehicle around the world triggers concern and interest in road safety, ease of mobility and environment impacts.
The direct impact can be seen through the increase of road accidents with high fatality rate. The alongside effect of road accidents generally associated with health service burden and claims as well as expenditure on repairing services on the crash damages and initiate liability to the national economy [3].

On the other hands, the increasing number of vehicles with lack of infrastructure development causes traffic congestion [4] and brings great challenges to transportation mobility and sustainability, causing a waste of time and fuel [5]. The increasing of fuel 
consumption leads to environmental impacts such as worsening air pollution due to the incomplete combustion in the vehicle produces carbon monoxide (CO) alongside with carbon dioxide $\left(\mathrm{CO}_{2}\right)$, hydrocarbon $(\mathrm{HO})$, and nitrous oxide $\left(\mathrm{NO}_{\mathrm{x}}\right)$. The stop-and-go driving practice due to traffic hindrance causes more fuel consumption and more emission [6].

The consequences of these traffic issues are affecting quality of life of people; research works are actively carried out in different countries on Intelligent Transportation System (ITS) to solve the issues raised by the rapid growth of worldwide vehicle ownership. ITS is an integrated intellectualized system with amalgamation of surveillance, communication and information technologies [7]. The application of ITS include Advanced Traffic Management System (ATMS) [7], Advanced Traveler Information System (ATIS) [8], Advanced Vehicle Control System (AVCS) [9], Commercial Vehicle Operation (CVO) [10] and Advanced Public Transportation System (APTS) [8]. Positioning technology is the most crucial element in these applications.

Global Positioning System (GPS) is the most common positioning approach [11] with worldwide availability and high accuracy. The widespread adoption of GPS technology in recent years [12] is also due to its improvement in term of accuracy, price and size. However, GPS has its drawbacks; the Non-Line-of-Sight (NLOS) and multipath effect problems [13] in buildings, tunnels, jungles or urban canyons. NLOS occurs when the satellite signals transmissions are totally blocked by obstacles while multipath effect is when the satellite signals are reflected by the surface of obstacles before the signal is received by GPS receiver [14] introducing a positioning error.

GPS receiver cannot perform under NLOS condition as no satellite signals can be received; the multipath effect causes the pseudo-range error between satellites and receiver antenna to be overestimated [13] as the signals had been scattered. Overestimation of pseudo-range error leads to GPS errors that degrade the GPS accuracy. Therefore, investigation on other positioning technologies is necessitated to resolve the shortcomings of GPS technology to meet the goal of continuous positioning in ITS applications. The positioning technologies can be categorized into three major types, which are the satellite-based positioning, network-based positioning and location prediction [15].

Satellite-based positioning is divided into Global Navigation Satellite System (GNSS) Regional Navigation System (RNS) and Satellite-based Augmentation System (SBAS). Meanwhile, the network-based positioning can be referred to the signals in Cellular Network (CN), Wireless Local Area Network (WLAN), and Vehicular Ad Hoc Network (VANet). In addition, the location prediction can be done through Inertial Navigation System (INS) and Artificial Intelligence (AI) system.

\section{Satellite-based Positioning}

\section{Global Navigation Satellite System (GNSS)}

GNSS is a generic term for satellite navigation systems which can provide location information with global coverage. Satellite receiver can identify its location through mathematical calculations involving the orbit and time information from a number of satellites of GNSS. The first GNSS in the world is GPS, which is developed by United State (US) in early 1970 [16]. GPS is initially conceived by Department of Defense (DoD) to provide accurate military navigation [17]. In the beginning of 1980s, US committed to make GPS available for civilian users [17] and become the pioneer of civilian navigation. Widespread adoption of GPS in civilian navigation has attracted attention of other countries and has raised their intention to develop their own GNSS. Table 1 exhibits available GNSS across the globe.

GPS provides Standard Positioning Service (SPS) to civilian users and Precise Positioning Service (PPS) to authorized military users [18]. Although civilian users can navigate with SPS, the implementation of Selective Availability (SA) degrades the GPS accuracy intentionally [19]; However SA was ceased on May 1, 2000 [20] and the SA removal has greatly improved the accuracy [21] of GPS from $100 \mathrm{~m}$ to $10-20 \mathrm{~m}[22]$.

Russia is triggered with the positioning technology and become the second country to owned GNSS, namely GLONASS. It launched its first satellite in October 1982 and completes the satellites constellation in 1995. However, GLONASS satellites constellation started to decay due to short design 
Table 1. Global Navigation Satellite System (GNSS)

\begin{tabular}{ccccc}
\hline Country & GNSS & Functionality & Satellites & Accuracy \\
\hline United States & GPS & Operational & 31 & $7 \mathrm{~m}$ \\
Russia & GLONASS & Operational & 29 & $6 \mathrm{~m}$ \\
Europe & GALILEO & In development & 30 & - \\
China & COMPASS & In development & 35 & - \\
\hline
\end{tabular}

lifespan. In 2008, there are only 13 operational satellites available [18]. Fortunately, reinvigoration of GLONASS constellation since 2001 [18] has recovered the capability of GLONASS navigation and its full-constellation operational is restarted in $2011[22]$.

European countries introduce their own GNSS called GALILEO and China developed COMPASS in realization of the significant and importance to have realizes the significance to develop their individual GNSS as well as contribute to worldwide navigation.

Currently, GPS and GLONASS are fully operational while GALILEO and COMPASS are in the process of development [23]. GPS has 31 operational satellites while GLONASS has 23 operational satellites with three spares, two in maintenance and one in test phase [25-26]. GALILEO estimated to have 27 operational satellites with three spares [27] whereas COMPASS expected to have 27 Medium Earth Orbit (MEO) satellites, five Geostationary Orbit (GSO) satellites and three Inclined Geosynchronous Satellite Orbit (IGSO) satellites [23].

Between the operational systems, GLONASS has slightly better positioning accuracy of $6 \mathrm{~m}$ as compared to GPS with accuracy of $7 \mathrm{~m}$ [28] but GPS has the advantage of being the most mature and established navigation system. The accuracy of GALILEO and COMPASS is expected to be higher than current operating systems.

Apart from fulfilling large demand of civilian users on navigation and its potential commercial market, GLONASS, GALILEO and COMPASS are developed to improve the accuracy of positioning system and reduce the dependency on GPS. Moreover, the integration of at least two GNSS can improve the performance of navigation. The combination of GPS and GLONASS for instance is a solution to the issue of limited visible satellites at single time and point.
Interoperation of the GNSS systems makes more satellites available and visible to satellite receiver with additional signals selection function to increase accuracy, stability, reliability, and operation speed. A dual-channel reconfigurable GNSS receiver is required to be reconfigurable to support all possible GNSS signals and incorporate two independent channels to receive incoming signals simultaneously [29]. With clear sky view, the accuracy of GNSS is promising. The only challenges of GNSS are NLOS of satellite signals and multipath effect. These challenges promote the innovation of implementing the Regional Navigation System (RNS) and Satellite-based Augmentation System (SBAS).

\section{Regional Navigation System (RNS)}

Regional Navigation System is an additional satellite constellation to improve the performance of existing GNSS over limited geographical area. It helps to increase the visibility of satellites in the view of receiver by the installation of Geo Synchronous Orbit (GSO) satellites or combination of Geo Stationary Orbit (GEO) and GSO satellites. There are two major RNSs, established; namely the Japan's Quasi Zenith Satellite System (QZSS) and India's Indian Regional Navigation Satellite System (IRNSS) [30]; details of the RNS are shown in Table 2.

Table 2. Regional Navigation System (RNS)

\begin{tabular}{ccc}
\hline Country & RNS & No. of satellites \\
\hline Japan & QZSS & 3 \\
India & IRNSS & 7 \\
\hline
\end{tabular}

The QZSS satellites are installed on three different GSOs which are 45 degree inclined to the equatorial plane with altitude of $35786 \mathrm{~km}$ from the surface of the Earth [18]. QZSS GSOs are highly elliptical as shown in Figure 1 and they are orbiting the Earth with the same speed as the Earth orbits. The orbiting satellites on GSOs forms a special figure-eightpattern ground track on the earth, as illustrated in Figure 2. 


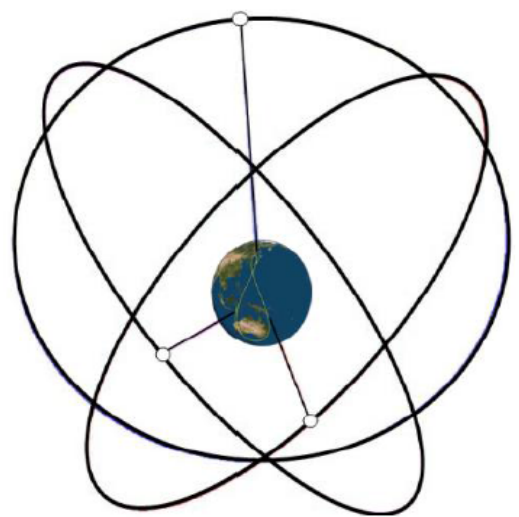

Figure 1. QZSS Constellation Source: Adopted from [31]

The asymmetric figure-eight-pattern ground track covered Japan with much smaller northern loop meanwhile Australia and New Guinea are widely covered by the larger southern loop [27]. The ground track has a central line at $135^{\circ} \mathrm{E}$ in longitude [18]. The QZSS is unique as at least one out of the three GSO satellites will be near the zenith over Japan all the time [24]. High elliptical characteristic of QZSS GSOs with high altitude makes the satellites to be further away from the Earth if compared to any other GNSS satellite constellations. These can raise the elevation angle of QZSS above $70^{\circ}$ in Japan [27]. Larger elevation angle reduces the probability of NLOS occurrence and thus improves the availability of positioning system.

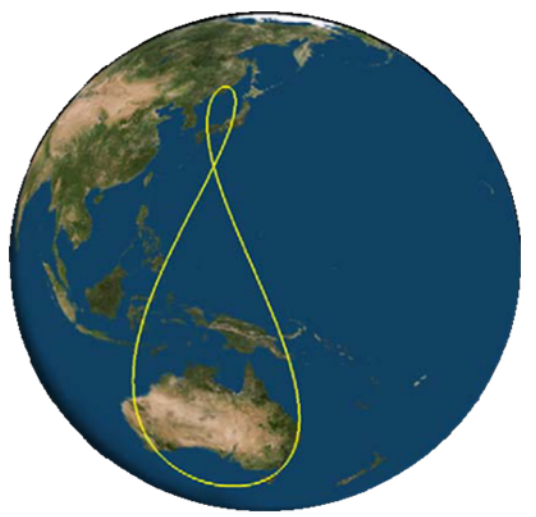

Figure 2. QZSS Ground Track

Source: Adopted from [31]

In contrast, IRNSS is planned to combine the use of GEO and GSOs by installing three satellites on GEO and four satellites on GSOs. Satellite on GEO supposes to be at the same point over the sky in the point of view of people on the Earth as they both orbits the identical center point with the equal speed and direction. The GEO satellites are anticipated to be placed on $34^{\circ} \mathrm{E}, 83^{\circ} \mathrm{E}$ and $132^{\circ} \mathrm{E}$ while the other four satellites are planned to be sited on GSOs which are inclined $29^{\circ}$ to the equatorial plane [27]. The location of GEO satellites and ground tracks using figure-eight pattern and its ground coverage (bounded by red dotted-line) is presented in Figure 3.

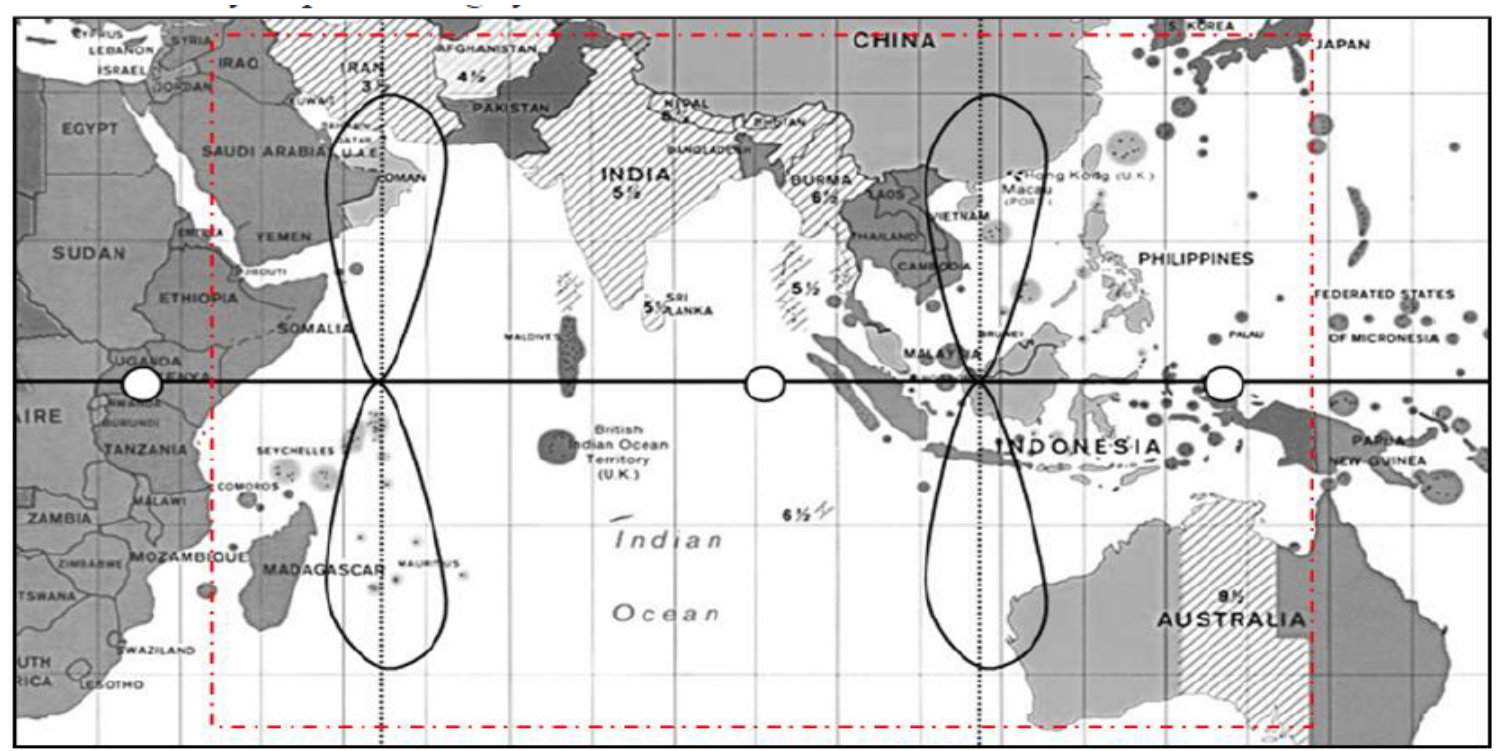

Figure 3. India's Indian Regional Navigation Satellite System (IRNSS) Satellite Constellation and ground coverage 
IRNSS is expected to provide absolute position accuracy better than $20 \mathrm{~m}$ throughout India [32]. With the IRNSS satellite constellation, seven satellites are assured to be visible throughout India. Positioning performance can be significantly improved by combining IRNSS with existing GNSS (GPS and GLONASS) as the number of visible satellites is raised up to at least 26 [33]. The higher visibility improves the availability, accuracy and reliability of positioning.

\section{Satellite-based Augmentation System (SBAS)}

The capabilities of GNSS are well known as it provides worldwide navigation service with adequate accuracy for the use of civilians. However, some shortfalls such as lack of civil international control and inadequate accuracy for aviation purpose prompted the need for GNSS performance enhancement [35]. SBAS is a suitable approach to improve the performance of GNSS. The major difference between RNS and SBAS is that SBAS has satellite constellation only on GEO. SBAS installs GEO satellites on equator to provide differential corrections, integrity parameters and ionosphere data [35] over a region spanned by a network of ground reference stations.
Reference stations are strategically positioned to monitor and measure satellite signals to be backhauled to master stations for error and correction calculations [36]. The generated correction message is sent to GEO satellites by uplink stations and broadcast the SBAS correction message on GPS frequency to improve the accuracy of GNSS positioning.

The seven countries have put their initiative on developing SBASs to supplement to existing GNSS. These SBASs has at least two satellites or at most five satellites on GEO. The total number of satellites that will be installed on GEO is estimated to be 20 . The locations of GEO and its respective countries satellites are disclosed in Table 3 .

The estimated coverage area of each SBAS is shown in Figure 4. MSAS and GAGAN with the least number of GEO satellites have the smallest coverage area. Although WAAS has the same number of satellites, the installation of more reference stations extends the coverage area. Other SBAS has wider service area with three or five GEO satellites and more reference stations.

Table 3. Satellite-based Augmentation System (SBAS)

\begin{tabular}{ccccc}
\hline Country & SBAS & Functionality & GEO & Longitude on Equator \\
\hline US & WAAS & Operational & 2 & $133^{\circ} \mathrm{W}, 107^{\circ} \mathrm{W}$ \\
Japan & MSAS & Operational & 2 & $140^{\circ} \mathrm{E}, 145^{\circ} \mathrm{E}$ \\
Europe & EGNOS & Operational & 3 & $15.5^{\circ} \mathrm{W}, 21.5^{\circ} \mathrm{E}, 64.5^{\circ} \mathrm{E}$ \\
India & GAGAN & In Development & 2 & $55^{\circ} \mathrm{E}, 83^{\circ} \mathrm{E}$ \\
Russia & SDCM & In Development & 3 & $16^{\circ} \mathrm{W}, 95^{\circ} \mathrm{E}, 167^{\circ} \mathrm{E}$ \\
Africa & ASAS & In Development & 3 & $15.5^{\circ} \mathrm{W}, 15^{\circ} \mathrm{E}, 65.6^{\circ} \mathrm{E}$ \\
China & SNAS & In Development & 5 & $58.75^{\circ} \mathrm{E}, 80^{\circ} \mathrm{E}, 110.5^{\circ} \mathrm{E}, 140^{\circ} \mathrm{E}, 160^{\circ} \mathrm{E}$ \\
\hline
\end{tabular}

Source: Adopted from [37] 


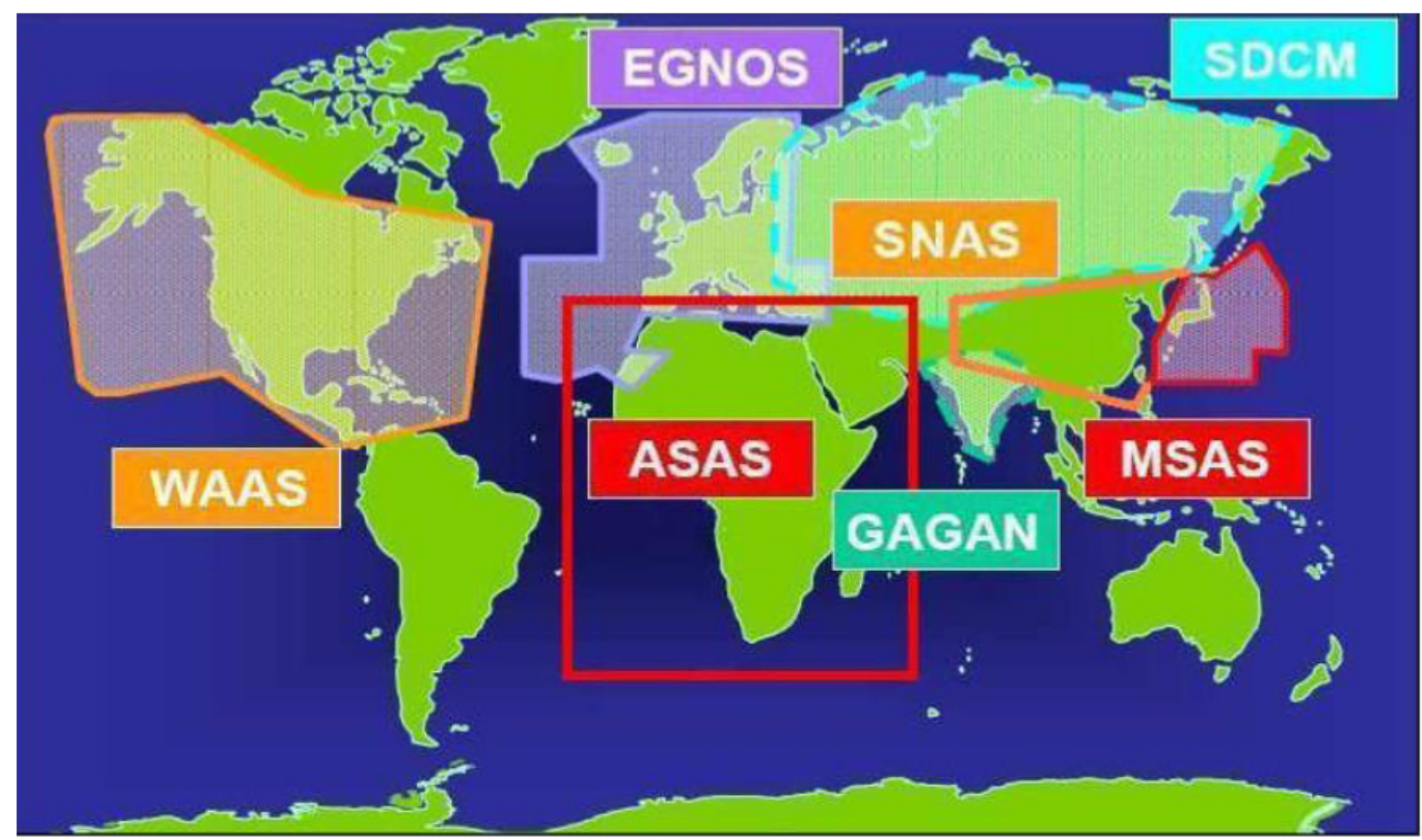

Figure 4.Satellite-based Augmentation System (SBAS) Coverage Area

Source: Adopted from [37]

\section{Network-based Positioning}

\section{Cellular Network (CN)}

Cellular Network $(\mathrm{CN})$ is based on a radio network distribution has been extensively extended for mobile positioning because of its reliability and commercial importance. With the well-founded cellular network and existing Global System for Mobile Communication (GSM) infrastructures, the investigation in $\mathrm{CN}$-based positioning is simpler than the installation of any satellite-based positioning system. Tremendous research interest on mobile positioning [28] using $\mathrm{CN}$ is motivated by its newsworthy technology as the location unknown of mobile station (MS) can be easily calculated with the existence of known position of the GSM base stations (BSs) [39]. However, the positioning method of a location is estimation with less accuracy if compared to GNSS, RNS and SBAS.

The location estimation is done through computation on the parameters of signal transmission between BS and MS. The signal transmission parameters that aids in location computation are Cell-ID, Received Signal Strength (RSS), Angle of Arrival (AOA), Time of Arrival (TOA), and Time Difference of Arrival (TDOA) [40].
The reliability and applicability of Cell-ID and RSS are high due to the reason that no further modification or investment is needed for their implementation. Cell-ID approach is supported by all current mobile phone while signal strength is always available because it is forwarded regularly for the handoff purpose [11]; therefore, no extra installation cost is required. On the other hand, AOA, TOA and TDOA techniques required the installation of additional hardware named Location Measurement Unit (LMU) at BS. For TOA and TDOA parameters LMUs must have a shared common clock reference with MS to achieve strict time synchronization between LMUs and MS. As network modification is required, the reliability is medium since the modification must be implemented at all BSs. However, this will increase the overall cost. The inability to implement modification at all BSs will contribute to low applicability. Moreover, the latency is higher because of the synchronization process. The major benefit of these three approaches is the improved accuracy if compared to Cell-ID and RSS. The performance of each CN-based approach is presented in Table 4 . 
Table 4. CN-based Positioning Approaches

\begin{tabular}{llllll}
\hline Techniques & Reliability & Applicability & Cost & Latency & Accuracy \\
\hline Cell-ID & High & High & Low & $<5 \mathrm{~s}$ & $100-1500 \mathrm{~m}$ \\
RSS & High & High & Low & $<5 \mathrm{~s}$ & $200-500 \mathrm{~m}$ \\
AOA & Medium & Low & High & $<10 \mathrm{~s}$ & $100-200 \mathrm{~m}$ \\
TOA & Medium & Low & Medium & $<10 \mathrm{~s}$ & $50-200 \mathrm{~m}$ \\
TDOA & Medium & Low & Medium & $<10 \mathrm{~s}$ & $50-150 \mathrm{~m}$ \\
\hline
\end{tabular}

Source: Adopted from [38]

Figure 5 shows the structure of CN-based positioning approaches. Cell-ID is the simplest technique as only one BS is required to estimate the location. The location estimation is according to the Cell Global
Identity (CGI) of MS such as Mobile Country Code (MCC), Mobile Network Code (MNC), Location Area Code (LAC), and Cell Identity (CI) [11].

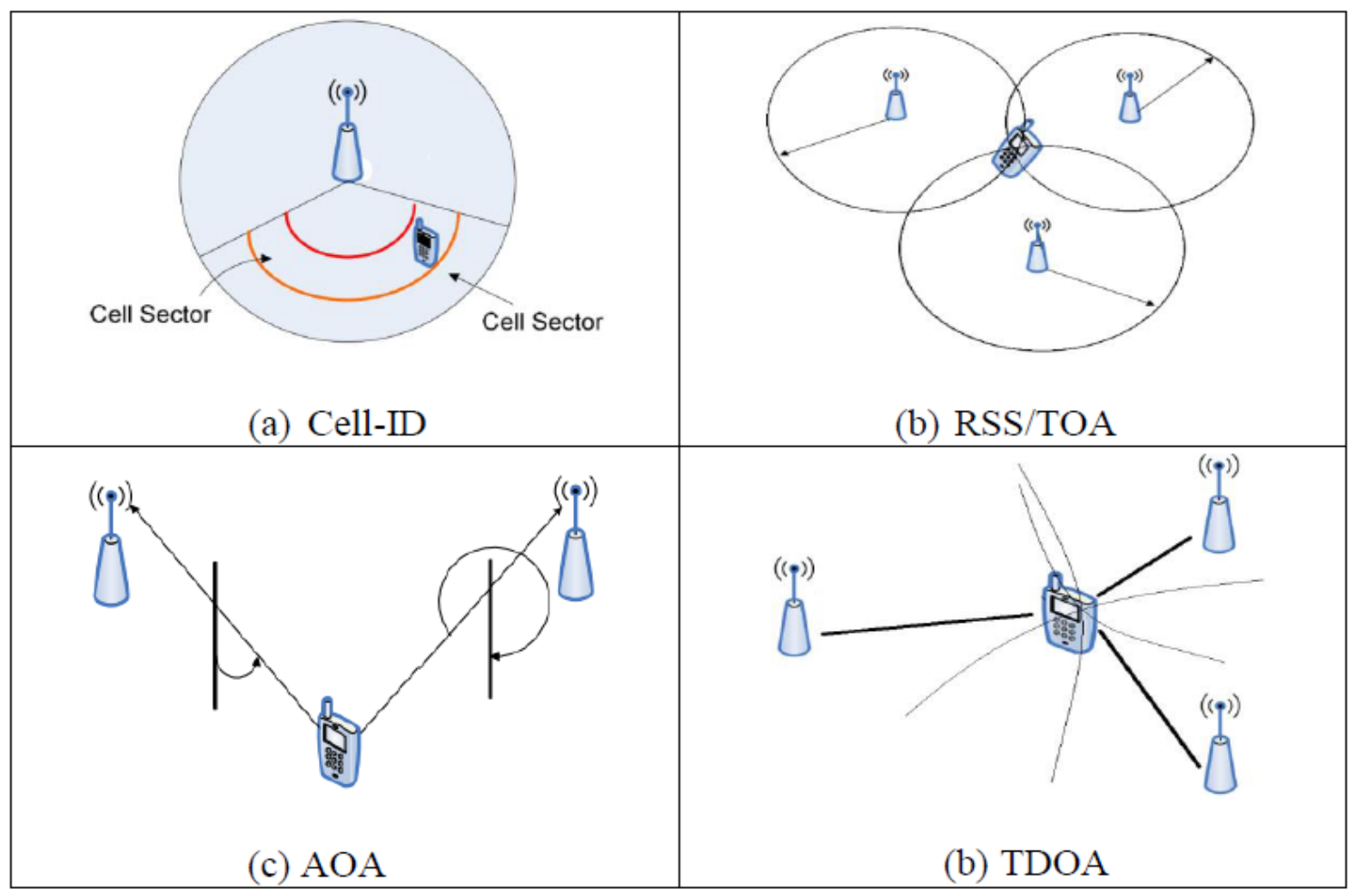

Figure 5. CN-based Positioning Approaches

Source: Adopted from [11]

Despite its simplicity, Cell-ID approach has the worst accuracy up to $1.5 \mathrm{~km}$; to enhance its accuracy, positioning error can be reduced using Timing Advance (TA) that measures the distance between MS and BS. TA is a number range from 0 to 63 and each increment of TA represents $554 \mathrm{~m}$ from BS [11] helps to narrow down the estimation range to a ring with radius of $554 \mathrm{~m}$. Both RSS and TOA require three $\mathrm{BSs}$ for triangulation computation (refer to Figure 5), whereas the MS location can be estimated by finding the intersection point of three signals from nearby BSs. The only difference is the computational parameters.

RSS calculates the location with signal strength while TOA uses the time of arrival from BSs to MS. RSS is less accurate as compared to TOA owing to the fact that signal strength is highly affected by the obstacles along the signal transmissions. The signal strength attenuation occurs as the results of path 
loss, multipath fading, and shadowing [41]. TOA requires the time of arrival to calculate the distance between the MS and three BSs respectively. The timing error strongly affects the distance calculation, which in turns will affect the precision of location estimation. The timing error may be caused by the clock synchronization error or propagation delay.

AOA approach can estimate the location with the signal elevation angle to two BSs. Though the number of BSs required is reduced, this method involves the use of specialized antenna arrays [42]. The requirement of this specialized hardware causes the AOA to be costly and not attractive to be widely implemented. Furthermore, a minor error in angle measurement would result in severe error in positioning. The condition is even worse if the NLOS problem occurs and angle measurement is unavailable.

TDOA has similar performance to TOA but with slight improved accuracy. The higher accuracy credited to the removal of timing error in TOA. The difference in the time of arrival of the signal at multiple LMUs is calculated respectively to determine the hyperbolic curves. The best intersection of hyperbolic curves is the estimated MS location.

Obviously, there are pros and cons of each $\mathrm{CN}$ based positioning technology. Consequently, the integration of different techniques is investigated by researchers to complement the limitations for better positioning performance. There are various hybrid CN-based positioning systems such as RSS/TOA [43], RSS/AOA [44], AOA/TOA [45], AOA/TDOA [46], and TOA/TDOA [47].

Since it is difficult to measure Line-of-Sight (LOS) signals from three BSs simultaneously, AOA algorithm that utilizes signals from two BS antenna arrays can be used to solve the problem of TOA and TDOA. When three or more BSs can be detected, TOA algorithm will be dynamically adjusted to perform positioning [48]. The implementation of AOA to augment RSS, TOA or TDOA is proved to perform better.

According to [49], the performance of standalone is worse than the RSS/TDOA, RSS/TOA, TOA/ TDOA and RSS/TOA/TDOA cooperative models [49]. Hybrid localization RSS/AOA/TOA/ TDOA schemes in cellular network shows a high improvement if compared to standalone technique [50]. The accuracy of the hybrid localization can be improved up to $73.6 \%$.

\section{Wireless Local Area Network (WLAN)}

In recent years, Wireless Local Area Network (WLAN) has become popular in the field of communication apart from cellular network [51] due to its easy installation and maintenance. The rapid development of WLAN has drawn researchers' attention towards positioning based on WLAN infrastructure as it has existing infrastructure that needs no further installation and investment. This would make the system cheaper and easier to be implemented.

WLAN-based positioning uses the similar approaches as $\mathrm{CN}$-based positioning. It performs position estimation by calculating the signal strength, time of arrival, angle of arrival, time difference of arrival of WLAN transmission to/from WLAN Access Points (APs) [52]. The difference between WLAN and $\mathrm{CN}$ is the signal transmission characteristics.

WLAN-based positioning is more common in indoor positioning applications, where satellite-based positioning has limitation of NLOS. The success of WLAN indoor positioning has attracted attention of researchers to implement this technology to outdoor positioning in order to overcome the limitations of existing positioning technology.

Both of the indoor and outdoor positioning techniques require a large number installation of WLAN APs with well-planned allocation of each AP in order to optimize the estimation results. The more APs can cover wider area of positioning and the exact location of APs helps in the positioning estimation.

Among the WLAN-based positioning techniques, Receive Signal Strength (RSS) is the simplest as no modification is needed yet it is difficult to have an ideal signal propagation medium. NLOS or multipath signal propagation causes error in RSS positioning, resulting in poor accuracy. Hence, location fingerprinting is designed to enhance the RSS approach. The key idea of this approach is approximates the location by comparing the RSS measured to a set of premeasured RSS values that is being store in the fingerprint database. The location 
fingerprinting is outperforming the standalone RSS because it can address some of the RSS problems.

The main difficulties of this system are the development and maintenance of the fingerprint database. The process of collecting the RSS data at calibration points and updating the database from time to time is a challenging task. The survey procedure of this method is time consuming as well [53]. Instead of traditional fingerprint database, there is a new design with added value of directional RSS information which can improve the average positioning error from $35.8 \mathrm{~m}$ to 23.5 $\mathrm{m}$. The test results presented by also shows that the fingerprinting can perform well in outdoor environment with positioning error of the tens of meter [54].

Despite the fact that WLAN has stronger signal in outdoor environment, the ever-changing environment with buildings, vehicles and people makes the signal transmission complex and affects the RSS. The slightly outdated traditional or directional fingerprint database can estimate the location with larger error.

The other techniques such as AOA, TOA, and TDOA are not preferred in WLAN-based positioning as a lot of efforts are needed in the modification on software and hardware of WLAN infrastructure. They are considered to have better accuracy in indoor environment. An indoor AOAbased WLAN positioning can have accuracy better than $2 \mathrm{~m}$ but its accuracy degrades as the distance between mobile receiver and WLAN infrastructure increases [56]. This shows its suitability to be indoor positioning scheme but not for complicated outdoor environment.

In addition, TOA and TDOA technique is good for indoor positioning because it gets rid of the multipath issue. Thereby, a WLAN positioning based on joint RSS and TOA system is proposed [52] because it improves the accuracy of the system without additional cost on firmware or hardware and it performs better in indoor instead of outdoor.

\section{Vehicular Ad Hoc Network (VANet)}

Vehicular Ad Hoc Network (VANet) is also called Inter-Vehicle Communications (IVC) or Vehicle-toVehicle (V2V) with the objective of enhancing the road safety [56]. VANet becomes the key for future Intelligent Transportation System (ITS) services. The advancement of communication technologies in VANet promotes the investigation of positioning using VANet.

There are various communication technologies that can be incorporated in VANet, such as WiFi, WiMax, WAVE, cellular, Bluetooth and Radio Frequency Identification (RFID). These communication technologies have different performance in terms of range (coverage), and data rate as shown in Table 5. Subsequently, different technology is deployed in different VANet applications.

Table 5. VANet Communication Technologies

\begin{tabular}{ccccc}
\hline Technologies & Protocol & Frequency Band (GHz) & Range (m) & Data Rate (Mbps) \\
\hline Cellular & GSM/GPRS/3G & $0.85 / 0.9 / 1.7 / 1.8 / 1.9 / 2.1$ & 15000 & 2.0 \\
WiFi & IEEE 802.11 & $2.4 / 5$ & 100 & 54.0 \\
Bluetooth & IEEE 802.15.1 & 2.45 & 100 & 1.0 \\
RFID & IEEE 802.15.4 & 2.45 & 10 & 0.1 \\
WiMax & IEEE 802.16 & $2.5 / 3.5 / 5.8$ & 50 & 72.0 \\
WAVE & IEEE 1609 & 5.9 & 1 & 27.0 \\
\hline
\end{tabular}

Source: Adopted from [57-60]

Since VANet applications are for vehicles with high mobility, the data transmission rate is crucial factor in consideration of communication channel implementation. Delivery latency also highly affects the reliability of the VANet positioning system. Though cellular, WiFi, and WiMax have the location computation ability, the process of computation and communication between vehicles is time consuming and power consuming. Therefore, these technologies are not suitable for positioning in VANet but can be used as communication between vehicle and road infrastructure to obtain the location information. 
Among the VANet communication technologies, cellular network has the lowest frequency bands (850/900/1700/1800/1900/2100 MHz). However, it has good BS coverage range up to $15 \mathrm{~km}$ with reasonable data rate up to $2 \mathrm{Mbps}$. It is not suitable as the communication medium in VANet is due to the burdening data charge rate of real-time transmission.

WiFi and WiMax have outstanding data rate than other communication technologies but Wireless Access Vehicular Environment (WAVE) is the most mature wireless technology that potentially meets the extremely short latency [61] and high data rate requirement of VANet positioning. Nevertheless, these technologies require continuous service fees for constant positioning.

Bluetooth and RFID are developed under IEEE 802.15 protocol with the same bandwidth of 2.45 $\mathrm{GHz}$. These two communication technologies offer the smallest coverage range and lowest data rate. As the Bluetooth data transmission needs signal synchronization between two terminals, it is not qualified in the high mobility vehicular environment. On the other hand, RFID has the potential to be the primary tool in vehicular communication service as it is implemented successfully and effectively in similar transportation application. The examples are RFID implementation in intelligent traffic management expert system [62], bus monitoring system [63], Electronic Toll Collection System (ETCS) [64] and public transit smart card [65].

RFID tags can be installed at the roadside with the exact coordinates respectively and the vehicle that is embedded with RFID reader can update its current location whenever it passes the tag. The small coverage range is sufficient to disseminate the location data from roadside infrastructure to approaching vehicles. Moreover, $100 \mathrm{kbps}$ data rate is adequate to transmit the instant location data to the reader. Besides, RFID is exploited to a RFGPS (Radio Frequency-GPS) localization system to calibrate the GPS error and improve the accuracy [66]. This system also allows the location data broadcasting to nearby vehicles that do not have GPS receiver, enabling non-GPS vehicles to estimate the location through single peer localization scheme.

The RFID offer many advantages such as free service following device installation as well as cheaper installation cost; no synchronization or encryption process is needed; simple to be executed and the extendibility of the system to be implemented with the adoption of RFID reader in vehicles.

\section{Location Prediction}

The earliest location prediction system is Inertial Navigation System (INS) which deploys accelerometers or motion sensors, gyroscopes or rotation sensors, and odometers or distance sensors to obtain acceleration, angular rate, and heading angle measurements for next location prediction [67]. This location prediction technique can also be known as dead reckoning.

Although INS is a self-contained system with a set of mathematical algorithms to forecast position information, it is not an ideal standalone system [68]. It has to be integrated with GPS to support the continuity of navigation especially during the GPS signal outages. INS provides high short term accuracy, high positioning update rate and immunity to external interference yet it has the limitation of accuracy degradation in long term due to deterministic and random error [69]. The deterministic errors occur due to uncompensated sensors' error, scale factor instability and misalignment. These errors can be minimized with calibration procedure but the random errors that happen naturally cannot be avoided or removed.

Kalman Filter (KF) is a mature data fusion model that uses a series of measurements to estimate an unknown variable with certain precision and accuracy. It has been highly applied in GPS/INS schemes either loosely-coupled mode or tightly couple mode [70]. KF can be considered as a benchmark for GPS/INS integration [69]. Apart from KF, there are extensions named Extended Kalman Filter (EKF) and Unscented Kalman Filter (UKF) which can work on non-linear system.

The Interactive Multi Model - Extended Kalman Filter (IMM-EKF) is proposed for the integrity of low cost GPS/SBAS/INS to allow consistency during high dynamic state of vehicle and reduce the unrealistic noise [71]. Tests are carried out to verify that IMM-EKF has better performance than Single Model (SM) - EKF [72]. The positioning error is reduced and the level of confidence on the solutions is increased. KF has some restrictions such as requisite of predefined accurate stochastic 
model as well as prior information of measurement covariance matrices for each new sensor [73]. During the system linearization process or system missmodeling, divergence of approximation results is possible. Consequently, the systems based on Artificial Intelligence (AI) have been suggested as solution.

The Adaptive Neuro-Fuzzy Inference System (ANFIS) is an AI-based system that is proposed to improve the performance of KF-based GPS/INS with fuzzy correction algorithm in the absence of GPS signals [74]. The ANFIS has a set of trained data about the evolution of INS errors in several scenarios to provide adaptive positioning. The ANFIS fuzzy correction system calculates the variation between INS data with the trained data to compute a location with minimized error probability. This system can execute a result with seven times better accuracy through the implementation of fuzzy correction [70]. The accuracy for position, velocity and angle are greatly enhanced.

In the past few years, inertial sensor based on Micro-Electro-Mechanical System (MEMS) has been considered to be implemented in INS/GPS navigation applications as it is commercially available at lower cost [69]. The performance enhancement with first order Gauss Markov (GM), second order Auto Regression (AR) and ANFIS is performed and compared. KF-ANFIS shows its outperforming over KF-GM and KF-AR with better accuracy and consistency over the trajectory [69]. Besides ANFIS, more systems based on Artificial Intelligence (AI) have been suggested as solution to KF-based GPS/INS scheme. The AI-based systems to assist KF include Radial Basis Function Neural Network (RBFNN) [75], Input-Delayed Neural Network (IDNN) [76] and so forth.

GPS/INS scheme that uses RBFNN as improvement solution is because of its simple architecture, universal approximation and fast training [77]. RBFNN is a feed forward three layers network, which comprises input layer, hidden layer and output layer [78]. Mapping is nonlinear from input to output while the output is linear to adjustable parameters. Even if RBFNN has been claimed as has fixed topology and lack of dynamicity, it does show accuracy improvement [76].

In contrast, IDNN has high complexity with higher accuracy because it holds the input data at the input layer through the input delay elements, allowing the output INS position to be modeled based on present and past samples [73]. IDNN has superior performance during short term and long term GPS signal outages if compared to other conventional and recent AI-based systems [69].

Another recent AI-based approach in KF-based GPS/INS is Wavelet-based Neural Network (WBNN). The wavelet de-noising is able to remove the noise and disturbance of the signal before it is sent to neural network. This method is claimed to have better performance than standalone $\mathrm{KF}$ as the de-noised information allows neural network to provide better approximation [79].

\section{CONCLUSIONS}

The necessity of global positioning technology in traffic management applications is crucial due to the increased number of vehicle worldwide. Tremendous amount of research works have been carried out to explore and improve the overall best methods for positioning. Satellite-based positioning system has offered the best accuracy, followed by network-based positioning and location prediction. GNSSs satellite positioning is developed by many countries to improve local positioning and reduce the dependency on GPS for positioning. However, the GNSS signal outages remains as an issue where further research needs to be performed. The network-based positioning with relatively low accuracy is suggested to reduce the gap. CN is a better option compared to WLAN and VANet; as its existing infrastructure has wider coverage around the world. In CN-based positioning, CellID and RSS approaches are suggested as they have high reliability, high applicability, low cost and short latency. Its limitation of low accuracy can be further improved with AI system. In addition, RNSs and SBASs are proposed to enhance positioning performance in term of availability, reliability, continuity, and accuracy. In the current stage, the integration of GPS/GLONASS with either RNS or SBAS is able to improved positioning accuracy. GPS/GLONASS/Cell-ID/RSS/INS with IDNN$\mathrm{KF}$ approach is suggested to be a solution for best positioning for traffic management applications. 


\section{ACKNOWLEDGEMENTS}

The author would like to thank Universiti Malaysia Sarawak (UNIMAS) who has funded this research under the Dana Principal Investigator (DPI), Grant No.: Dana Principal Investigator (DPI)-02 (DPI15)873/202(07).

\section{REFERENCES}

1) Davis, S. C., Diegel, S. W., Boundy, R. G. (2011). Transportation Energy Data Book: Edition 30. Oak Ridge National Laboratory, Oak Ridge, Tennessee.

2) Davis, S. C., Diegel, S. W., Boundy, R. G. (2012). Transportation Energy Data Book: Edition 31. Oak Ridge National Laboratory, Oak Ridge, Tennessee.

3) Saifizul, A. A., Yamanaka, H., Karim, M. R. (2011). Empirical Analysis of Gross Vehicle Weight and Free Flow Speed and Consideration on its Relation with Differential Speed Limit. Accident Analysis and Prevention $\mathbf{4 3}$ (3): 1068-73.

4) Leung, H., El Faouzi, N. E., Kurian, A. (2011). Intelligent Transportation System (ITS). Information Fusion 12 (1): 2-3.

5) Shah, N., Kumar, S., Bastani, F., Yen, I. L. (2012). Optimization Models for Assessing the Peak Capacity Utilization of Intelligent Transportation Systems. European Journal of Operational Research 216 (1): 239-251.

6) Li, C., Shimamoto, S. (2012). An Open Traffic Light Control Model for Reducing Vehicles' $\mathrm{CO}_{2}$ Emissions Based on ETC Vehicles. IEEE Transactions on Vehicular Technology 61 (1): 97-110.

7) Shah, A., Jongdal, L. (2007). Intelligent Transportation Systems in Transitional and Developing Countries. IEEE A\&E Systems Magazine on Aerospace and Electronic Systems, pp. 27-33.

8) Lee, W. H., Tseng, S. S., Shieh, W. Y. (2010). Collaborative Real-Time Traffic Information Generation and Sharing Framework for the Intelligent Transportation System. Information Sciences 180 (1): 62-70.
9) Garcia-Ortiz, A., Amin, S. M., Wootton, J. R. (1995). Intelligent Transportation Systems Enabling Technologies. Mathematical Computer Modeling 22 (4): 11-81.

10) Wootton, J. R., García-Ortiz, A., Amin, S. M., (1995). Intelligent Transportation Systems: A Global Perspective. Mathematical and Computer Modelling 22 (4-7): 259-268.

11) Samiei, M., Mehrjoo, M., Pirzade, B. (2010). Advances of Positioning Methods in Cellular Networks. International Conference on Communications Engineering, pp. 174-178.

12) Serr, K., Windholz, T., Weber, K. (2006). Comparing GPS Receivers : A Field Study. URISA Journal 8 (2): 19-23.

13) Pinana-Diaz, C., Toledo-Moreo, R., Betaille, D., Gomez-Skarmeta, A. F. (2011). GPS Multipath Detection and Exclusion with Elevation-Enhanced Maps. 14th International IEEE Conference on Intelligent Transportation Systems, pp. 19-24.

14) Giremus, A., Tourneret, J. Y. (2005). Joint Detection/Estimation of Multipath Effects for the Global Positioning System. Proceedings of IEEE International Conference on Acoustics, Speech, and Signal Processing, pp. 17-20.

15) Irfan, M., Baig, M., Khan, F., Hashmi, R. (2009). Management of Location Based Advertisement Services using Spatial Triggers in Cellular Networks. International Journal of Computer Science and Information Security 6 (1): 181-185.

16) GPS: The First Clobal Navigation Satellite System. (2007). 935 Stewart Drive Sunnyvale, California 94085: Trimble Navigation Limited.

17) Shaw, M. (2004). Modernization of the Global Positioning System. Acta Astronautica 54: 943-947.

18) Hegarty, C.J., Chatre, E. (2008). Evolution of the Global Navigation Satellite System (GNSS). Proceedings of the IEEE 96 (12): 1902-1917. 
19) Herron, P., Powers, C., Solomon, M. (2001). Global Positioning Technology in the Intelligent Transportation Space. Intelligent Vehicle Technologies. Elsevier Ltd., USA, pp. 229-255.

20) Ochieng, W.Y., Sauer, K.. (2002). Urban Road Transport Navigation: Performance of the Global Positioning System After Selective Availability. Transportation Research Part C: Emerging Technologies 10 (3): 171-187.

21) Asakura, Y., Hato, E. (2004). Tracking Survey for Individual Travel Behaviour using Mobile Communication Instruments. Transportation Research Part C: Emerging Technologies 12 (3-4): 273-291.

22) Wang, J. J. H. (2012). Antennas for Global Navigation Satellite System (GNSS). Proceedings of the IEEE 100 (7): 2349-2355.

23) Gao, G. X., Enge, P. (2012). How Many GNSS Satellites are Too Many? IEEE Transactions on Aerospace and Electronic Systems 48 (4): 2865-2874.

24) Li, B., Zhang, S., Dempster, A. G., Rizos, C. (2011). Impact of RNSSs on Positioning in the Asia-Oceania Region. Journal of Global Positioning Systems 10 (2): 114-124.

25) Information-Analytical Centre. (2012). GPS Constellation Status, 12.12.2012. Available at: http://www.glonass-ianc.rsa.ru/en/GPS/ (Accessed on 12 December 2012).

26) Information-Analytical Centre. (2012). GLONASS Constellation Status, 12.12.2012. Available at: http://www.glonass-ianc.rsa.ru/ en/GLONASS/ (Accessed on 12 December 2012).

27) Prades, C. F., Presti, L. Lo, Falletti, E. (2011). Satellite Radio localization from GPS to GNSS and Beyond: Novel Technologies and Applications for Civil Mass Market. Proceedings of the IEEE 99 (11): 1882-1904.

28) East-West Digital News. (2011). Glonass Sets Goal to Exceed GPS Accuracy Twofold; Vice PM Guarantees Free Service
Worldwide. Available at: http://www.ewdn. com/2011/06/02/glonass-sets-goal-to-exceed-gps-accuracy-twofold-vice-pm-guarantees-free-service-worldwide/ (Accessed on 3 November 2012).

29) Qi, N., Xu, Y., Chi, B., Xu, Y., Yu, X., Zhang, X., Xu, N., Chiang, P., Rhee, W., Wang, Z. (2012). A Dual-Channel Compass/GPS/ GLONASS/Galileo Reconfigurable GNSS Receiver in $65 \mathrm{~nm}$ CMOS with On-Chip I/Q Calibration. IEEE Transactions on Circuits and Systems I: Regular Papers 59 (8): 17201732.

30) Öcalan, T., Tunalıglu, N. (2010). Data Communication for Real-Time Positioning and Navigation in Global Navigation Satellite systems (GNSS)/Continuously Operating Reference Stations (CORS) Networks. Scientific Research and Essays 5 (18): 26302639.

31) Inaba, N., Matsumoto, A., Hase, H., Kogure, S., Sawabe, M., Terada, K. (2009). Design concept of Quasi Zenith Satellite System. Acta Astronautica 65 (7-8): 1068-1075.

32) Babu, R., Rethika, T., Rathnakara, S. C. (2012). Onboard Atomic Clock Frequency Offset for Indian Regional Navigation Satellite System. International Journal of Applied Physics and Mathematics 2 (4): 270-272.

33） Rao, V. G., Lachapelle, G., Kumar, V. (2011). Analysis of IRNSS over Indian Subcontinent. ION ITM, pp. 1-13.

34) Benedicto, J., Michel, P., Ventura-Traveset, J. (1999). EGNOS Project Status Overview. Air and Space Europe 1: 58-64.

35) Cezón, A. A., Cueto, M., \& Hidalgo, I. (2010). SACCSA - SBAS in the CAR / SAM Regions: Feasibility Analysis. 23rd International Technical Meeting of the Satellite Division of The Institute of Navigation, pp. 2002-2012.

36) Blanch, J., Walter, T., Enge, P. (2012). Satellite Navigation for Aviation in 2025. Proceedings of the IEEE 100: 1821-1830. 
37) Ilcev, S. D. (2011). Comparison between Extension of the European EGNOS and New African ASAS Network for Africa and Middle East. 2011 IEEE International Conference on Microwaves, Communications, Antennas and Electronic Systems (COMCAS), pp. 1-2.

38) Adusei, I.K., Kyamakya, K., Jobmann, K. (2002). Mobile Positioning Technologies in Cellular Networks: An Evaluation of Their Performance Metrics. Proceedings MILCOM 2002, pp. 1-6.

39) Juang, R., Lin, D., Lin, H. (2007). Hybrid SADOA/TDOA Mobile Positioning for Cellular Networks. IET Communications 1 (2): 282-287.

40) Bshara, M., Orguner, U., Gustafsson, F., Biesen, L. V. (2011). Robust Tracking in Cellular Networks Using HMM Filters and Cell-ID Measurements. IEEE Transactions on Vehicular Technology 60 (3): 1016-1024.

41) Mendoza, H. P. (2011). Distributed Localization for Wireless Distributed Networks in Indoor Environments. Virginia Polytechnic Institute and State University.

42) Ibrahim, M., Youssef, M. (2012). CellSense : An Accurate Energy-Efficient GSM Positioning System. IEEE Transactions on Vehicular Technology 61 (1): 286-296.

43) Kbar, G., Mansoor, W. (2005). Mobile Station Location Based on Hybrid of Signal Strength and Time of Arrival. Proceedings of the International Conference on Mobile Business, pp. 585-591.

44） Wang, S., Jackson, B. R., Inkol, R. (2012). Hybrid RSS/AOA Emitter Location Estimation Based on Least Squares and Maximum Likelihood Criteria. 2012 26th Biennial Symposium on Communications (QBSC), pp. $24-29$.

45) Al-Jazzar, S., Ghogho, M., McLernon, D. (2009). A Joint TOA/AOA Constrained Minimization Method for Locating Wireless Devices in Non-Line-of-Sight Environment. IEEE Transactions on Vehicular Technology 58 (1): 468-472.
46) Cong, L., Zhuang, W. (2002). Hybrid TDOA/ AOA Mobile User Location for Wideband CDMA Cellular Systems. IEEE Transactions on Wireless Communications 1 (3): 439-447.

47) Tseng, P. H., Feng, K. T. (2010). Hybrid TOA/TDOA Based Unified Kalman Tracking Algorithm for Wireless Networks. 21st Annual IEEE International Symposium on Personal, Indoor and Mobile Radio Communications, pp. 1707-1712.

48) Deng, P., Fan, P. Z. (2000). An AOA Assisted TOA Positioning System. International Conference on Communication Technology Proceedings, pp. 1501-1504.

49) Laaraiedh, M., Yu, L., Avrillon, S., Uguen, B. (2011). Comparison of Hybrid Localization Schemes using RSSI, TOA and TDOA. Wireless Conference 2011 - Sustainable Wireless Technologies (European Wireless), pp. 626630 .

50) Chen, J., Abedi, A. (2010). A Hybrid Framework for Radio Localization in Broadband Wireless Systems. IEEE Global Telecommunications Conference GLOBECOM 2010, pp. 1-6.

51) Retscher, G., Kealy, A. (2005). Ubiquitous Positioning Technologies for Intelligent Navigation Systems. Proceedings of the 2nd Workshop on Positioning, Navigation and Communication and 1st Ultra-Wideband Expert Talk, pp. 99-108.

52) Uthansakul, P., Uthansakul, M. (2009). WLAN Positioning Based on Joint TOA and RSS Characteristics. International Journal of Electrical and Computer Engineering 4 (15): 942-949.

53) Wen, L. P., Nee, C. W., Chun, K. M., Shiang-yen, T., Idrus, R. (2011). Development of Handheld Directory System Built on WiFi-Based Positioning Techniques. International Journal of Computers and Communications 5 (3): 188-197.

54) Li, B., Quader, I. J., Dempster, A. G. (2008). On Outdoor Positioning with Wi-Fi. Journal of Global Positioning Systems 7 (1): 18-26. 
55) Wong, C., Klukas, R., Messier, G. G. (2008). Using WLAN Infrastructure for Angle-of-Arrival Indoor User Location. IEEE 68th Vehicular Technology Conference, pp. 1-5.

56) Li, F., Wang, Y., 2007. Routing in Vehicular Ad Hoc Networks : A Survey. IEEE Vehicular Technology Magazine, pp. 12-22.

57) Hossain, E., Chow, G., Leung, V. C. M., McLeod, R. D., Mišić, J., Wong, V. W. S., Yang, O. (2010). Vehicular Telematics over Heterogeneous Wireless Networks: A Survey. Computer Communications 33 (7): 775-793.

58) Ward, M., Kranenburg, R. V., Backhouse, G. (2006). RFID : Frequency, Standards, Adoption and Innovation.

59) Papadimitratos, P., La Fortelle, A., Evenssen, K., Brignolo, R., Cosenza, S. (2009). Vehicular Communication Systems: Enabling Technologies, Applications, and Future Outlook on Intelligent Transportation. IEEE Communications Magazine, pp. 84-95.

60) Sichitiu, M. L., Kihl, M. (2008). Inter-Vehicle Communication Systems: A Survey. IEEE Communications Surveys \& Tutorials 10 (2): 88-105.

61) Li, Y. J. (2012). An Overview of the DSRC/ WAVE Technology. Social Informatics and Telecommunications Engineering, pp. 544558.

62) Wen, W. (2010). An Intelligent Traffic Management Expert System with RFID Technology. Expert Systems with Applications 37 (4): 3024-3035.

63) Mustapha, A. M., Hannan, M., Hussain, A., Basri, H. (2010). UKM Campus Bus Monitoring System using RFID and GIS. 6th International Colloquium on Signal Processing \& its Applications (CSPA), pp. 62-66.

64) Kamarulazizi, K., Ismail, W. (2010). Electronic Toll Collection System using Passive RFID Technology. Journal of Theoretical and Applied Information Technology, pp. 7076.

65) Pelletier, M. P., Trépanier, M., Morency, C. (2011). Smart Card Data Use in Public Tran- sit: A Literature Review. Transportation Research Part C: Emerging Technologies 19 (4): 557-568.

66) Lee, E. K., Oh, S. Y., Gerla, M. (2012). RFID Assisted Vehicle Positioning in VANETs. Pervasive and Mobile Computing 8 (2): $167-$ 179.

67) Faouzi, N. E. El, Leung, H., Kurian, A. (2011). Data Fusion in Intelligent Transportation Systems: Progress and Challenges - A Survey. Information Fusion 12 (1): 4-10.

68) Malleswaran, M., Vaidehi, V., Mohankumar, M. (2011). A Hybrid Approach for GPS/INS Integration using Kalman Filter and IDNN. 2011 Third International Conference on Advanced Computing, pp. 378-383.

69) Noureldin, A., Karamat, T. B., Eberts, M.D., El-Shafie, A. (2009). Performance Enhancement of MEMS-Based INS/GPS Integration for Low-Cost Navigation Applications. IEEE Transactions on Vehicular Technology 58 (3): 1077-1096.

70) Hiliuta, A., Landry, R., Gagnon, F. (2004). Fuzzy Corrections in a GPS/INS Hybrid Navigation System. IEEE Transactions on Aerospace and Electronic Systems 40 (2): 591-600.

71) Toledo-Moreo, R., Zamora-Izquierdo, M. A., Ubeda-Minarro, B., Gomez-Skarmeta, A. F. (2007). High-Integrity IMM-EKFBased Road Vehicle Navigation with LowCost GPS/SBAS/INS. IEEE Transactions on Intelligent Transportation Systems 8 (3): 491-511.

72) Toledo-Moreo, R., Zamora-izquierdo, M. A., Gomez-skarmeta, A. (2006). IMM-EKF Based Road Vehicle Navigation with Low Cost GPS/INS. 2006 IEEE International Conference on Multisensor Fusion and Integration for Intelligent Systems, pp.433-438.

73) Noureldin, A., El-Shafie, A., Bayoumi, M. (2011). GPS/INS Integration Utilizing Dynamic Neural Networks for Vehicular Navigation. Information Fusion 12 (1): 48-57. 
74) Noureldin, A., El-Shafie, A., Reda Taha, M. (2007). Optimizing Neuro-Fuzzy Modules for Data Fusion of Vehicular Navigation Systems using Temporal Cross-Validation. Engineering Applications of Artificial Intelligence 20 (1): 49-61

75) Sharaf, R., Noureldin, A., Osman, A., ElSheimy, N. (2005). Online INS/GPS Integration with a Radial Basis Function Neural Network. IEEE A\&E Systems Magazine, pp. 8-14.

76) Malleswaran, M., Angel. D. S., Manjula, S. (2010). Integration of INS and GPS Using Radial Basis Function Neural Networks for Vehicular Navigation. 11th International
Conference on Control Automation Robotics \& Vision (ICARCV), pp. 2427-2430.

77) Sharaf, R., Noureldin, A. (2007). Sensor Integration for Satellite-Based Vehicular Navigation using Neural Networks. IEEE Transactions on Neural Networks 18 (2): 589-594.

78) Wang, W. (2009). Vehicle Type Recognition Based on Radial Basis Function Neural Networks. 2009 International Joint Conference on Artificial Intelligence, pp. 444-447.

79) Zhang, T., Xu, X. (2012). A New Method of Seamless Land Navigation for GPS/INS Integrated System. Measurement 45 (4): 691701 . 